\title{
Global Bioethical Prevention of the Collision of Biological and Cultural Evolution on Miserable Human Survival
}

\author{
James E. Troskoa
}

\begin{abstract}
With the cultural myth that science can only determine the way the world "is" (facts), while humanities, social sciences, lawyers, philosophers, and theologians must determine the way the world "ought to be" (values), those in position of global-, national-, and local-political power make major decisions of the use (or non-use) of scientific knowledge and technology. As a result, the human being has created a non-scientifically based cultural environment that is affecting his ability to survive. In effect, cultural evolution is occurring more rapidly than biological evolution that can adapt to the changes brought about in the physical and psycho-social environments. In a pluralistic cultural world, where each society has generated a different view of human nature and different ethical values, the use, misuse, or non-use of scientific and technological advances are derived from these unscientific views of human nature. Since all life depends on limiting interacting environmental and ecological factors, it is imperative that scientific information be used to govern how to minimize irreversible effects on life-sustaining ecological factors, but also scientific information bearing on understanding human nature ought to be integrated into a "global bioethics". While ethical values cannot be directly derived from scientific factors, it is also true that human values or our "ought" cannot be maintained in ignorance or defiance of the facts or the "is".
\end{abstract}

\section{Keywords}

Global bioethics, scientific concepts of human nature, genetic and environmental interactions, one health-one planet, human impact on earth's ecosystem

Right now we're living in what Carl Sagan correctly termed a demon-haunted world. We have created a Star Wars civilization but we have paleolithic emotions, medieval institutions, and a godlike technology. That's dangerous. [E. O. Wilson, talking with Slate about altruism and enlightenment (April 30, 2012)]

Curiosity without compassion is inhumane; however, compassion without curiosity is ineffective. (Victor Weisskopf 1972 Science 176: 138-146)

\section{THE MORAL CRISES: COLLISION OF CULTURAL EVOLUTION WITH OUR BIOLOGICAL EVOLUTIONARY ROOTS}

While it appears that the current state of human

aMichigan State University, USA

\section{Correspondent Author:}

James E. Trosko, Department of Pediatrics and Human Development, College of Human Medicine, Michigan State University, East Lansing, Michigan 48824, USA

E-mail: james.trosko@ht.msu.edu 
existence might seem to be liken to a deer caught in the head lights of a car, in that the deer, being paralyzed by the moment and not being able to respond appropriately to escape the moment, fortunately, human beings have the potential ability to think about the past and imagine the future. We are not prisoners of the moment. Yet, we human beings do seem to be caught in the eye of a hurricane but unable to see what is about to happen. How can this be, when, in this age of global information exchange, every human being has seen natural and human-made disasters, such as starvation due to droughts, life disruptions due to earthquakes, floods, wars, and political repressions on human choices? It is though our ability to draw upon our ability to think about the past and to plan for a sustaining future has been clouded by some false views of the past and future.

It is a fact that current physical and chemical resources, which are needed to maintain all life on our earth, are finite or in fragile conditions. In addition, it is also true that the qualitative and quantitative nature of those resources have changed from the first day of Earth's creation to the day life first appeared. While non-human life contributed to utilizing these resources and to altering the ecosystem, the impact of non-human life on the ecosystem, on which all life depends, although not insignificant (i.e., role of phytoplanktons to shift our atmosphere from an non-oxygen atmosphere to an oxygenated atmosphere), has been minuscule, both with regard to scale and time, compared with that which has been altered by the appearance of Homo sapiens. Therefore, it can be said that while non-humans leave behind their existence some detritus and ecosystem changes, that detritus has been basically bio-degradable and life was able to adapt to the changes. Yet, human existence creates a non-biodegradable detritus, such as "walls" (physical structures and abstract ideas). These "walls", then, create and force new human existence. Today, an individual or a society finds it difficult to develop its own (personal or cultural) view of the world because those rather indestructible "walls" of our ancestors shaped our early socialization. Therefore, the rather obvious state of our current global survival, being jeopardized by an exploding human population, global pollution of air, water, limiting nutritional foods, miserable human existence for billions of human beings (Potter 1988), unrealistic or bankrupt ideologies, philosophical/political theories, religious theologies (Sagan 1995; Trosko 2002; Trosko 1984), and being exacerbated by natural disasters (recent tsunami in Japan), needs a new vision as to how, on one hand, to prevent the serious threat to decent human existence survival, and on the other hand, to plan for a sustainable ecology to meet an ever changing impact on our limiting physical and chemical resouces.

The paper the author is proposing is that recycling soft drink bottles, training more psychologists and ecologists, and building more high-tech military forces will not ameliorate the human psychosocial and ecological problems of today or the future (Trosko 1975). We must address the causes of this current and foreseeable human survival problem, and not waste too much of our valuable time and limited resources attacking the symptoms of what led us to this state. That is to say, we ought not to try to understand what led us to the current state of affairs, but, rather to use our current ability to analyze critically, using all of our scientific disciplinary knowledge, what really contributes to all our global problems. It is the author's fundamental assumption that the "cause" of our multiple, interacting global problems, resides in our head in the form of a view of human nature that is, quite frankly and factually, in conflict with our scientific knowledge of the biological basis of human beings (Trosko 2002). This view has been expressed by many other scholars, including John Passmore, who stated that:

Whitehead would have agreed, I think that it is impossible to put forward any political or moral theories without making assumptions about the nature of man. The concept or model may be awkward; it may be slippery; it 
may be indefinite. But since we cannot avoid employing some model of man, tacitly if not explicitly, it is important to be aware of what we are doing and to consider what implications may be latent in the models we have available for use. (Passmore 1970)

Therein lays the fundamental issue, in that human beings, no longer a prisoner of biological "instincts" but is a "designing", cultural being, having created different "cultures" via its Diaspora from Africa to live in different physical environments. Each specific location of these human beings, in arid, temperate, and cold environments, created unique "walls" or worldviews/life philosophies and religions to control and guide human behavior, in order to survive in each of these physical environments. We, therefore, have to acknowledge that we live in a pluralistic world of different primitive, pre-scientific world views, philosophies, and religions to shape our moral values. Within those who claim that religion is their source of ethical decision-making, there are literally thousands of "religions", with 21 major formal religions among them. With about five billion people claiming to belong to one of those religions and about one billion claiming no formal supernatural or formal institutional religion to shape their ethical philosophy, there is now an obvious starting point of identifying the problem that has created the crisis in the distruction of our ecological environment.

While some argue that just because there are so many different religious and philosophical/political world views, and all seem to have very different concepts of human nature, their ethical principles and moral values are basically the same. This seems patently false and influenced by wishfully thinking in trying to defend their bankrupt view of human nature. In addition, others would argue that there is no such thing as "human nature" ["Man has no nature; he has a history" (Ortega y Gassett 1941)]. Moreover, other have argued that even if humans have a "nature", who will determine what it is or whose religious or philosophical/political world view is the correct one.
Even more complexing, how can any view of human nature actually provide the principles to shape ethical behavior to prevent further destruction of our environment and to help shape a future that will minimize human misery and lead to a more sustaining ecological environment? However, the author makes the assumption, as others have (Rhinelander 1974; Pellegrino 1963; Geertz 1965; Cassirer 1956; Alexander 1971), that each individual holds a view of human nature, which shapes policies and practices of human intervention, and which in turn influences biological and psycho-social development.

\section{AS OUR INSTITUTIONS DECAY, IS OUR SENSE OF RIGHT AND WRONG CRUMBLING AS WELL}

It has been said that while many non-human life forms are conscious, only human beings seem to be conscious of their consciousness. So while all life forms, from single cell bacteria to bonobo apes do make impacts on the Earth's ecosystem, only humans, with their unique attributes: [(1) to have abstract thinking by creating symbols to represent concrete objects; (2) to communicate those abstractions via languages; (3) to convert those abstractions into "things"; and (4) to make choices as to use or not use those things, or to make value decisions], can make the kind of impacts on the ecosystem, needed for our requirements for life that can jeopardize our own existence. All of these attributes of being human, especially the latter (our ability to value) will have either short- or long-term consequence on our environment, which in turn will impact on all of us, positively, negatively, or both (Trosko 1984).

It is now well-established that the earliest life forms emerged from a very hostile environment, having to generate life-self-replicating molecules (nucleic acids) and cells from simple molecules in an environment, characterized by radiations, gravity, an atmosphere without oxygen, temperatures and 
molecules needed to produce energy for life. All this had to occur with a delicate balance to maintain the integration and stability of those life-assuring genetic-DNA (deoxyribonucleic acid) codes, with the chance of some disruption of those DNA codes, in order to provide individuals in a population that could survive inevitable changes in the environment. It must be stated with great emphasis that all DNA, including that which codes for the human species, is subject to both genetic change (mutations) and altered gene expression (epigenetic changes). Human DNA is not immune to these changes, therefore, it is subjected to inevitable environmental changes (physical, social, and cultural). One specific example was the transition from an anaerobic environment to an oxygen-rich environment caused by the evolutionary appearance of oxygen-producing life forms (Nursall 1959). This then helped to select new forms of life that could utilize oxygen to produce energy for life. To make a long evolutionary story short, eventually the primate ancestors to the Homo sapiens occurred.

\section{TWO COMPONENT BRAIN, ONE MIND AND MULTIPLE CULTURES}

In recent times, a phase "two cultures" has been used to characterize what might be perceived as one of the primary root causes of contempory global problems created by human existence. In his controversial book The Two Cultures, C. P. Snow (1959) sought to find an explanation for problems caused by the inability to resolve the fundamental problem between "facts" and "values" or between the "is" and "ought" (Bronowski 1965). Traditionally, that bifurcation has been placed on those that hold a "scientific" philosophy as a world view and those that are shaped by a "humanistic world view". Understandably, both terms are not concise, making this bifurcation problematic. While there might not exist universal accepted definitions of either term, "scientific" or "humanistic", in general, science is thought to be a human, self-correcting process of expaining observations or ideas so that testable predictions can be made. Scientific ideas are not uniquely personal. There is no such thing as Chinese science, Italian science, Brazilian science, or Japanese science. A scientific fact or idea must be applicable by all and it is a socially derived acceptance of something that is applicable anywhere on Earth or the Universe, $\mathrm{F}=\mathrm{MA}$ in Rome, Beijing, New York, and on Venus.

Equally important to realize is that all scientific facts are, on one hand, always incomplete. On the other end of the spectrum, a scientific "fact" can be dead wrong. Values, while some feel can be absolute and universal, are not necessarily tested to be "universal", nor they cannot be tested.

Another way to look at these complex distinctions between science and the humanities, facts and values, and the "is" and "ought", is to look at the pyschological means to generate a creative idea (fact or concept of value). Creativity is a product of the human brain, a product of being "human" (Bronowski 1965). Creativity is not a proprietory characteristic of either the scientific process or humanistic artistic process. It is a process of being human. While a scientist can have a "leap of the imagination", he/she must bring his/her feet back to the earth. On the other hand, an artist also can have a leap of the imagination, but he/she does not have an obligation to bring his or her feet back to earth. To be scientific, an idea must be tested publically, and be shown to be universally applicable until proven to be falsified. A song, poem, painting, or theological idea has no verifiable obligation to be accepted.

Clearly, one could argue that there exists more than "two cultures" that split human beings from one another. However, this bifurcation has proven useful to start to examine the complexities of the human condition and its relationship to human existence in a fragile ecosystem needed to maintain life. This basic assumption for this analysis brings to mind a story of Albert Einstein.

After delivering a lecture on his theory of 
relativity to a lay audience, a young reporter came up to Professor Einstein. "Professor Einstein, now that you physicists understand the workings of the Universe, don't you think it is 'complicated'?". Einstein, looked at the reporter and said: "Young man, when you know nothing of the Universe, it is, indeed, complicated! However, when you begin to understand the Universe, it is meerly complex!".

Therefore, the C. P. Snow's The Two Cultures is now hypothesized in this Commentary, as being, not only between the scientific and humanistic world views, but between two biological entities, generated by evolution of the human being. At the root of the current problem of the "two cultures" is the inability of evolutionary biologists and neuroscientists to convince, at the most fundamental level, all people of the world that the human brain is composed of two very different components of the brain. Therein lays the problem. It could be within the framework of the original "two cultures" gap, in that it takes sophisticated education and training to understand the science behind both evolution and the biological development of the brain. For those who never had the opportunity to get this kind of sophisticated education, or for those who are unable to learn these concepts or, finally, for those who have the ability to understand these concepts but who have major philosophical barriers to the concept of evolution, a split is down the line of a scientific versus "non-scientific" world view.

In addition, one must take into account the two components of the human brain, the primitive or "animal brain" and the "modern brain", have made for "strange bed fellows". The primitive brain was selected for by constantly changing non-cultural environmental forces, and is responsible for unconscious, automatic adaptive or "instinctual" behaviors, responsible for biological individual and species survival. During the million of years that pre-humans survived, the environmental changes challenged the primitive brain to respond unconsciously or "instinctually", until the development of a new biological process that coincided with the development of the modern brain. This new brain matter was built upon, and was connected to, the genetically hard-wired neurological processes that allow these pre-humanoids to survive. Teilhard de Chardin stated:

Admittedly the animal knows. But it cannot know that it knows - this is quite certain while animals "know", they do not "know they know". (Dobzhansky 1967)

This new level of the modern brain provided new processes to work with other non-brain anatomical evolutionary advances, or lack thereof walking on two legs, opposable thumbs, poor eyesight, poor sense of smell, etc. Included in these new evolutionary associated brain functions were the processes of: (1) self and death awareness and the ability to abstract; (2) translation of abstractions into symbols; (3) translation of symbols into things; and (4) making value choices with these symbols and things (Trosko 1984).

The emergence of cultural evolution from biological evolution has not been an easy or a seamless transition. Fundamentally, it is because cultural evolution or the human ability to create new information that provides short- and long-term consequences, impacts on the biological information locked in our genes, which is very slow to change adaptively. This is seen with the concept of "walls". "Men build walls, but walls build men" (Flusserr 1974). The non-human animals, which leave biological detritus, however, for the most part, it decays and has little influence on the next generation. On the other hand, the human being creates long-lived physical and abstract "cultural detritus", which can imprison future generations in physical and symbolic environments that restricts the survival potential and their individual potential as a creative individual or a humane civilization. As Ortega y Gasset has stated:

Man can not escape his biological evolutionary past and 
to a large extent can not break from his cultural past. (Platt 1972)

This brain is functioning primarily on biological information, stored in the DNA of both the germ cells and somatic cells of this brain. Upon the biological appearance of the higher functional brain, which not only made the individual aware of self, but also aware that he/she is aware of self. This new brain, while connected to the "animal" brain, is involved in producing and storing "cultural" information. To be able to escape the immediacy of the present, which was the function of the new brain, allowed one to remember the past and to dream of future states. While the two brains are not just two collections of independently functioning brain cells, it has been difficult to distinguish how one brain functions might affect the other. Whether one's conscious actions that can affect the subconscious functions of the brain, as seems to be the case with meditation, or by one's providing rationalizations for one's physiological responses created by the subconscious reactions, false concepts, created by the modern brain, has led to the idea that "free will" actually exists, when in reality, the "feeling" that one has free will is actually influenced by information locked in the primitive brain that acts as a "oven" to influence the experience of cultural information locked in the modern brain (Platt 1972; Harris 2012).

With the new potential technology of stem cell therapy to treat various human diseases, some have claimed that diseases such as Alzheimer's disease, might be "cured" by brain stem cell therapy. While some stem cell therapies will probably be possible, this Alzheimer's disease, is one that will probably not be treated by stem cell intervention. The idea is informative, in the respect that it gives an insight to our individual human nature and our perception of "self".

Imagine if brain stem cell therapy was available, when a man at the age of 50, was diagnosed with
Alzheimer's disease and had lost all conscious perception of self and his past, friends, and family. After a clinical successful implanting of neuronal stem cells, one would not have restored his sense of self or his past memories of friends and family. Rather, the "successful" stem cell therapy might have restored his function to collect new experiences and store them for future use. However, while he might have regained the function of acquiring experiences, he would not recover his historically unique experiences that forged his original sense of self. He would only be a " 50 year old baby". He would be able to start all over again to develop a new sense of who he might become. He will be a new person.

This should have a major philosophical impact on the non-scientific culture's sense of human nature. Our being or sense of self was not pre-ordained with a "soul", but it was created post conception. Only after our self-conscious started to acquire unique historical personal experiences in the social/cultural environments in which we find ourselves, does one develop a sense of who we are as an individual. Therefore, even with new stem cell therapy's restoration of the process of developing a sense of self, one could never re-create the historic experiences that created our original sense of self. Moreover, all of us, who continuously integrate new information into one's sense of self, have an ever-changing sense of self. Others who never have the ability, opportunity, or will to open up to new information to change one's sense of self, find themselves with a sense of living in a meaningless world. In addition, young children, who are in unstable social environments, might never receive positive signals from their environments to generate a strong sense of self.

\section{INTERACTING MODERN BRAIN WITH THE PRIMATIVE BRAIN AND THE FALSE DICOTOMY OF “FACTS AND VALUES”}

Today, more than ever before, the urgency of 
identifying the causes of chaos that is occurring on this human-occupied biosphere of Earth is too obvious. We must address the causes, not the symptoms. C. P. Snow was correct in pointing out that because of the cleavage and chasm between two cultures, the ethical systems of those, who really make the ultimate decisions to use or not use powerful scientific knowledge and technologies, are derived from non-scientific views of human nature. Given that, in our pluralistic world, most of which have access to use knowledge and technologies for short-term political/practical benefit, have different philosophical, theological, and political views of human nature, which ignore what modern sciences are saying about our human nature (Trosko 1984; Trosko 2002).

In our Western roots, it was Kant that cemented the cleavage between science and the humanities, between "fact" and "values" when he stated:

Consequently, Kant seemed to have no alternative but to set up morality and religion as independent autonomous actions, having no connection with science. This occurred in Kant's The Critique of Practical Reason. This point is tremendously important because it explains why the modern human being came to the notion of an autonomous ethics and religion having no basis in science. (Northrop 1959)

Human nature has both a genetic and an ever-changing and interactive cultural component. Human genetics makes human consciousness possible. Human consciousness makes possible an almost infinite number of cultural environments. However, because the genetic component of human nature is rather limited, in comparison to the conscious component, it is imperative that the cultural manifestations of consciousness (which includes our ethical and moral concepts) take into account the aforementioned realities of our human nature.

Our global problem resides in views of human nature that contradicts what modern sciences are saying about the biological/social nature of being human (Dobzhansky 1967). This has been succinctly stated many times. While one might find the suggestion that human nature can be identified by the sciences as nonsense, such as in the statement by Jose Ortega y Gassett: "Man has no nature, he only has a history" (Ortega y Gassett 1967), actually, this statement supports the idea that human nature is composed of the biological information in his genes, acquired through successful adaptive selection, as well as via the cultural information, he acquires in the unique historical/social history of which he is a part. This is further supported by John Platt when he stated (Platt 1966):

$\ldots$ in this sense, human nature is indeed constant. Its constancy lies in its adaptability to the environments we set up. (Platt 1966: 160)

James Drane (1972) has stated:

Every ethic is founded in a philosophy of human nature points toward ethical behavior.

Further, Leon Eisenberg elegantly noted the role in culture in shaping our view of human nature when he stated:

The planets will move as they always have whether we adopt a geocentric or heliocentric view of the heavens. It is only the equations we generate to account for those motions that will be more or less complex; the motions of the planets are sublimely indifferent to our earth-bound astronomy. But the behavior of man is not independent of the theories of human behavior that men adopt. (Eisenberg 1973)

John Dewey also saw that the cleavage of facts and values, caused by the two cultures, will continue to create a major problem of survival. He was not implying that scientists were actually making the decisions to use or not to use science/technology, but by those who were not educated in the scientific process, in the potential consequences and in the implications of science and technology. They were using these powerful ideas and technologies for 
short-term pragmatic gain.

A culture which permits science to destroy traditional values but distrusts its power to create new ones is destroying itself. (Taverne 2009)

This creates major problems, not only on the ecology, but on the individual's sense of meaning and their psychic world view: Max Otto (1947) pointed this out when he stated that:

The universe is run by natural forces and laws, not by moral laws. However, human societies, which live in the natural world, must live by moral laws. If those moral laws contradict or ignore the natural laws, it will be the human societies, not the physical universe, (or the global ecology) which will suffer the consequences of such defiance. (Otto 1947)

In most cases, most of the erosion of every culture's historic non-scientific views of human nature, by the use of scientific information and powerful technologies, causes a "psychic black hole". As a result, traditional religious and classic philosophical world views become more and more irrelevant (Enis 2008). This then leads to what ought to be done, namely, a new role of how science must be taught. John Tonsor said it best when he stated:

If we are to act ecumenically, let us begin not with theology but with ethics. Let us put ethics at the center of our undergraduate curricula and stress the ethical implications of all post-secondary education, whether it is broadly humanistic or narrowly vocational. If we cannot agree on how to act, there is little hope that we shall agree on what we are to believe. (Tonsor 1974)

Herein lays the major problem of the two cultures. If the unscientific views of human nature are somehow convincingly challenged by the scientific view in the non-scientific culture (the humanist intellectuals, as well as the uneducated masses), they are left with a moral "psychic black hole", a person without an "ethical compass" or a sense of purpose or meaning in life. Without the ability to understand scientific symbols and their meaning, the individual is left trying to defend the indefensible or is left with no sense of meaning or purpose. How does a non-believer live in a world of no "purpose". He focuses on to make his life meaningful and forgets the after life. Gunter Stent (1969) saw how this is happening even within science:

Thus we may perceive another internal contradiction in science: The innate axioms on which our brain bases its cognition of the outer world and from which springs common sense suffer ever-greater violation as the evolution of the physical research unfolds. This process causes, in turn, a progressive estrangement from the reality of that outer world, loss of psychic meaning of the insights gained into its operation, and hence weakening of the intensity of interest in probing further into its phenomena. (Stent 1969)

\section{A similar insight was stated by Arthur Koestler:}

The new territory opened up by the impetuous advances of a few geniuses, acting as a spearhead, is subsequently occupied by the solid phalanxes of mediocrity, and soon the revolution turns into a new orthodoxy, with the unavoidable symptoms of one-sidedness, overspecialization, loss of contact with other provinces' knowledge, and ultimately, estrangement from reality. (Koestler 1964)

As the Hubble space telescope has been readied for reaching to the beginning of time, the cosmological significance of its findings to date has failed to alter the perceptions of the "common sense" perception of human existence and human meaning in life for the billions who have seen the photographs. "Seeing", in this case, is not believing! Lastly, Robert Oppenheimer reiterated this dilemma in Levine and Thomas' book The Scientist vs. the Humanist (Levine and Thomas 1963: 149):

To sum up the characteristics of scientific knowledge today, then, I would say that it is mostly new; it has not been digested; it is not part of man's common knowledge; it has become the property of specialized communities who may on occasion help one another but who, by and large, pursue their own way with growing intensity further and further from their roots in ordinary life. 
One might use as examples of this idea, the recent "discovery" of the Higgs boson and the speculative "string theory" as a theory of everything, as illustrative of the above insights.

This is truly a serious psychological problem in a world, where everyone has access to, and is affected by, powerful technologies that know no social or cultural boundaries. The creation of a virtual world by the internet will have consequences we can not imagine. This is seen vividly by John R. Platt (1966):

To know if an act is good, it is therefore necessary to know what its consequences are, spreading out as far as possible into the future. High morality depends on accurate prophecy. But the future becomes more and more uncertain the farther we look. Any prophecy has half-life or time-constant, beyond which it cannot be trusted more than any random guess. In times of revolution, the half-life is short; in times of peace and stability it is long. This is why the accepted rules of morality change toward the personal and the immediate in times of great emergency and uncertainty. There is little point in sacrificing the present good to the long-run better, if the long run is totally uncertain and is just as likely to be made worse by our sacrifice.

\section{THE UNIVERSITY'S CHALLENGE TO BRIDGING THE TWO CULTURES}

While C. P. Snow's conceptualization of the "two cultures" has been analyzed and criticized thoroughly from both sides of the gap, there should be no doubt that he brought important issues that permeate many, if not most, of global, human religious, philosophical, ethical, psycho-social, cultural, and ecological issues. As has been recently summarized, one of the criticism with the "two cultures" problem is not the ignorance in understanding the second law of thermodynamics by most of the non-scientist population of the world, but the basic understanding of how science works and of the power and limitations of what is referred to as the "scientific process" (There is no "one" technique or procedure by which a natural observation is explained in naturalistic terms so that useful and testable predictions can be made) (Snow 1964) Taverne gets to the heart of the matter when he stated:

... science is one of the pillars of civilization and liberal democracy, as the eminent philosophers of science, Karl Popper, convincingly argued. It is, he said, "One of the greatest spiritual adventures man has yet known". Because science rejects claims to truth based on authority and depends on the criticisms of established ideas, it is the enemy of autocracy. Because scientific knowledge is tentative and provisional, it is the enemy of dogma. Because it is the most effective way of learning about the physical world, it erodes superstition, ignorance, and prejudice, which has been at the root of the denial of human rights throughout history, whether through racism, chauvinism, or the suppression of the rights of women. Nothing could have better illustrated the gap between cultures than the literary critic's, F. R. Leavis's view that science is concerned only with "productivity, material standards of living, hygienic and technological progress". (Taverne 2009)

Arthur Koestler summed up this problem of the gap between the "two cultures", when he stated:

However, the absurd division of our society into the "two cultures" produced the paradoxical phenomenon that the average educated person will be reluctant to admit that a work of art is beyond the level of his comprehension; but he will in the same breath and with a certain pride confess his complete ignorance of the principles which make his radio work, the forces which make the stars go round, the factors which determine the heredity of his children, and the location of his viscera and glands. One of the consequences of this attitude is that he utilizes the products of science and technology in a purely possessive, exploitive manner without comprehension or feeling. (Koestler 1964)

This is particularly disturbing when one recognizes that those in position of political power, who make decisions on the use (non-use or misuse) of scientific knowledge and technology, are exactly those who know little of the scientific values its process and of the long-term consequences on the ecology and human survival. In all fairness, so as not to be naive in blaming only the humanist population for not understanding the scientific world view, it should also be noted that even today, very sophisticated scientists 
have non-scientific views of human nature, from which of their values spring. While the highly educated "humanists", who can articulate, beautifully, some abstract rationale for ethical behavior, which might be consistent with a less sophisticated empirical ethical set of behaviors by uneducated individuals, if either ignore scientific understanding of human nature, the end result will be the same... They both will suffer the consequences of the misuse of powerful technologies.

Mr. "Buckley"-well-spoken, intelligent, curious, had heard virtually nothing of modern science. He had a natural appetite for the wonders of the Universe. He wanted to know about science. It's just that all the science had gotten filtered out before it reached him. Our cultural motifs, our educational system, our communications media had failed this man (and, I might add, most of the world's population!)... He knew nothing about how science works. (Sagan 1995)

Northrop seems to have identified the problem that needs to be solved when he succinctly defined the three types of theory that have separated the "two cultures":

There is the theory of natural sciences, from which the discovery of technological instruments, such as the atomic bomb, is derived. There is also the factual theory of social science, designating the de facto state of affairs in society. There is, finally, the normative theory of the humanities and social science, designating the humanistic and social ends, the correct or good form of social organization, not yet perfectly actualized in fact, at which we should aim. (Northrop 1959)

By noting that natural science theories are always being generated, always incomplete and changeable by self-correction, this will always impact on the physical, psychic, and social worlds. The "factual" theories of social science are also forever changing, as human existence in a physical/ecological world is always changing. Thus, if the normative theories of the humanities and social sciences that have been "cast in concrete as being absolute" to shape the "good form" of social organization in a snap-shot of time, that describes the adaptive behavior for that particular physical/ecological world, do not change, then, human adaptability will be challenged.

As C. P. Snow had also pointed out, the problem also exists between the "two cultures" within science and technology (Snow 1964). This is seen most recently between the Robert Openheimer and Edward Teller on the use of the atomic bombs. Although we will never know the concepts of human nature or the world views that generated the ultimate ethical principles of either scientist, there should be no doubt that both were brilliant scientists, as far as their discipline of physics is concerned, again, this points to the "two cultures" within any category of disciplines or categorical grouping of people.

Van R. Potter, writing for "The Interdisciplinary Studies Committee on the Future of Man" at the University of Wisconsin, also pointed this out in the article "Purposes of the University" (Potter et al. 1970). The answer to this challenge was:

The primary purpose of the university is to provide an environment in which faculty and students can discover, examine critically, preserve and transmit the knowledge, wisdom, and values that will help ensure the survival of the present and future generation's improvement in the quality of life.

J. Bronoswski said it poignantly when he said:

The shame is theirs who appeal to other values than the human imaginative values which science has evolved. The shame is ours if we do not make science part of our world, intellectually as much as physically, so that we may at last hold these halves of the world together by the same values. For this is the lesson of science, that the concept is more profound than its laws and the act of judging more critical than the judgment. (Bronowski 1965)

\section{John Tonsor indicated:}

If we are to act ecumenically, let us begin not with theology but with ethics. Let us put ethics at the center of our undergraduate curricula and stress the ethical implications of all post-secondary education whether it is 
broadly humanistic or narrowly vocational. If we cannot agree on how to act, there is little hope that we shall agree on what we are to believe. (Tonsor 1974)

\section{As Van R. Potter stated:}

While it is true that human "values" or the "ought's" can not logically flow from scientific "fact" or that the "is" can determine which values are right or wrong (so-called "Naturalistic Fallacy"), it is also true that human values or our "ought's" cannot be maintained in ignorance or defiance of the facts or the "is". (Potter 1988)

He coined the term, "bioethics" to help bridge the two cultures gap and the gap between the facts and values (Potter 1971). The essence of the conceptual breakthrough was by abandoning a pure abstract philosophical/theological rationalization of ethical principles, which ignored the human being as the ethicizing animal, living, inextricably, in a changing physical, biological, and cultural world. In effect, he postulated that one must account for the biological basis of the ethicizing animal in the ethical reasoning process, whose effect on individual and social behavior will have both short- and long-term positive and negative consequences. Later, the quotation by Roger Sperry, pyschobiologist, seems to be relevant at this point when he stated:

When subjective values are conceived to have objective consequences in the brain, they no longer need be set off in a realm outside the domain of science. The old proposition that science deals with facts, not with values, and its corollary, that value judgments lie outside the realm of science, no longer apply in the new framework. Instead of separating science from values, the present interpretation (When all the various ramifications and logical implications are followed through) leads to a stand in which science becomes the best source, method, and authority for determining ultimate value and those ultimate ethical axioms and guideline beliefs to live and govern by. By the word, science, I refer broadly to the knowledge, understanding, insight, and perspectives that come from science. But, more particularly, I am thinking of the principles for establishing validity and reliability and credibility of the scientific way as an approach to truth, insofar as the human brain can comprehend truth. (Sperry 1975)

To put this concept of "bioethics" as a "bridge" between the two cultures, the formulation by Northrop could not have been articulated any better:

In other words, in a properly constructed society, the philosophy which underlies the definition of one's economic doctrine, one's political doctrine, one's religious, poetic, and artistic theory must be identical with the philosophy of the natural sciences which is determined by nothing more than the logical analysis of the experimentally verified theories of the natural sciences to bring out their primitive, ontological assumptions and their methodological and epistemological assumptions.... One tragedy of our civilization is that whereas natural science has gone forward, the separation of the departments of knowledge has obscured the essential connection between ideological or humanistic philosophy and the philosophy of natural science. As a consequence, our ideological philosophies have not changed along with changes in our philosophy of the natural sciences. Thus, we find ourselves with sets of normative ideas grounded often in outmoded philosophies or in partial philosophies which get into conflict with each other. Hence, the conflict of moral and social ideologies. (Northrop 1959)

Levine and Thomas identified our task when they stated:

Our problem in our search for wisdom is to blend these two traditions in the minds of individual men and women. Many colleges and universities are trying to do just this, but there is one serious defect in the method. We pour a little of this and a little of that into the student's mind in proportions which result from mediation between departments and from the particular predilections of the deans and the president. We then hope that these ingredients will combine through some mysterious alchemy and the result will be a man educated, well-rounded, and wise. Most often, however, these ingredients remain well-separated in the compartmentalized mind, or they form an indigestible precipitate which is not only useless but possibly harmful, until time the healer washes it all away. (Levine and Thomas 1963)

\section{WHERE OUGHT THIS ODYSSEY LEAD}

While using the "two cultures" gap between the 
scientific and humanistic intellectuals was only a means to highlight that growing scientific and technological advances will always have impacts on all aspects of human social categories, even with scientists, within and between disciplines, it really boils down to the gap between those accepting scientific values and means of knowing and verifying ideas of the natural world, including human's biological nature and human's dependence for existence and survival in the natural world. In effect, this gap really refers to which means of knowing best gives humans the greatest chance of survival with justice and dignity. The major thesis of this exercise is that the "two cultures" gap is between those who accept the scientific views of human nature versus those that do not understand or accept those views.

These scientific models of human nature, e.g.:

(1) Nature and nurture view of human nature, not nature verse nurture, this view notes that all of human traits are the products of the interactions of genetic potentials locked in the DNA and the unique historical environmental factors (physical, chemical, biological, and psycho-social-cultural);

(2) Hierarchical view of human nature. This view conceptualizes that all the higher order features of human beings are "emergent" properties of the organization of atoms, molecules, organelles, cells, tissues, organs, organ systems, mind-consciousness, self-awareness, abstracting ability, language, and valuing, in other words, the whole is greater than the sum of its parts;

(3) Cybernetic view of human nature. At all levels of the hierarchical nature of the human being, there is a feedback homeostatic system between our biology and the physical-psycho-social environment;

(4) Bio-symbolic view of human nature. Humans live not only in a physical universe, but also in a symbolic or abstract universe of his own making;

(5) Bio-cultural evolutionary view of human nature. The bio-cultural evolutionary view is that a biological evolutionary aspect of human biology is constantly interacting with the cultural evolutional changes that humans make (Trosko 1984).

It is this interaction of glacier-speed biological evolution with laser-speed cultural evolution that is creating our current global crises (Trosko 2014).

These models are scientific in that they explain the observations of the natural, biological nature of the human being, which can lead to testable predictions. In that sense, they are scientific models, in that they can be falsified a definition of being scientific. There are no "supernatural" components of these models. Any philosophical, humanistic, religious models of human nature, which cannot be tested or falsified and which are not consistent with the scientific model, must be viewed with great skepticism. These non-scientific models of human nature have been historically at the foundations of far too many world views that generated ethical rules and values that have suppressed the human potential. Racist, chauvinistic, and prejudiced views have been spawned from these non-scientific views.

One needs only to single out the societal "ethical" views of homosexuality as being the result of a voluntary choice an individual makes and of the results of being "taught" as to how to be a homosexual. Yet, that view comes from the same society that never questions the fact that heterosexuality is not learned but innate in "good" persons who are heterosexuals. Yet we know that "male-ness" and "female-ness" are genetically determined by chromosomes. "Manhood" and "Womanhood" are culturally defined terms. However, being a heterosexual man or woman is the result of those genes/chromosomes interacting with the environment. One does not need to be taught how to be heterosexual human being. If that interaction with the environment leads to altered expression of those genes during development, the male-ness/female-ness might still determine the physical genitalia, but not the brain-hormone determinants of a self-awareness of manhood or womanhood. In other words, being a homosexual is 
not the result of being taught to be one, nor that one be taught how to reject this perception of self. This hypothesis is scientific, in that it can, and will, ultimately, be tested. Hormones, coded by genes, do make a difference during development on the genitalia. It, in all likelihood, makes a difference on other organs during development, such as the brain. In turn, this hormone-hard-wired brain will make other changes later in life. If during development, the natural expression of these critical hormone interactions is disturbed, later consequences on behavior might be noted. The DES (diethylstilbestrol)-treated pregnant women gave rise to daughters who were at high risk to vaginal cancers later in life (Cousins et al. 1980). This is great example of the "Barker hypothesis" (Barker 2004), which states that in utero exposures to environmental factors can lead to altered phenotypic states later in life.

Trying to learn from the ancient Greeks' view of the best manner to govern human behavior, i.e., via democratic means, they clearly noted that a democracy will only survive with an "informed electorate". In today's world, with science and technology, generating so much information and "stuff", and consequently, options (with short- and long-term individual and population/ecological consequences) in every discipline (some have very abstract implications, such as our place in the cosmic scheme of things) to detailed methodologies for reducing suffering from various diseases, it is impossible for any one individual (very educated to totally uneducated) to be informed as to whether to use or not use that information/technology.

Re-stating the obvious that: (1) all human decisions contain two components, namely the facts related to the decision to be made and the values that will guide the factual component; and (2) the values to render that decision cannot be derived by any strict calculus from science, ultimately, even if "informed" electorates really knew all that is humanly possible or relevant to the decision-making process, it is the value decision (i.e., the political decision) that is the final arbiter. Science and facts alone will never be enough to be the sole factor in decision-making in a democracy. If it is important to remember at this stage, that all "facts" are "value-laden" and all values are "experientially"- or "factually"-laden. Therefore, again, at best, all scientific facts are incomplete; at worse, they can be dead wrong. However, the values to ultimately affect the use or non-use of the knowledge, in not only a democracy, but in a pluralistic world, will determine the future success and quality of survival of both the current and future generations. To make this clear, two individuals (or two democracies) have exactly the same factual knowledge of the issue at hand, could vote to use or not use the facts, based on their different values.

While C. P. Snow clearly pointed out that he could have generated categories of people into at least "two thousand gaps" (Snow 1964), it seems in reality, the only one that really counts in the context of this commentary is the gap between those: (1) that accept all aspects of human nature as being "knowable" in naturalist terms by the sciences that can study and ultimately come to some universally-accept claims on the nature of human nature; and (2) that accept only some supernatural claims of human nature, human purpose, and human destiny (Forrester 2000).

This then also raises extremely complex definitions related to the ethical/moral values that spring from these "scientific" views of human nature and "supernatural" views of human nature. Those that always seem to cloud all debates are the terms, religion, and spirituality. Religion, all too often, relates to institutional doctrines concerning: (1) having a supernatural beginning of a human's life; views of life's purpose and of the here-after; and (2) set of proscriptive theological rationale and practical moral codes for earthly behavior. Within this view, if you do not adhere to the former, then clearly, you have no "moral grounding or moral compass" to shape 
your earthly behavior in any justifiable moral basis. Therefore, can an atheist, agnostic, or even a supernatural believer of another "faith" system lead a moral life? The answer is, of course, a person without the need to rely on ways of "knowing" a supernatural well-spring of religiosity, can lead a moral life, based on understanding the scientific view of human nature and human's intimate and delicate connection to all the forces of the natural physical, chemical, biological, psychological, ecological, social, and cultural worlds.

Therein lays the problem. Once an individual, convinced by one compelling scientific fact that challenges a "faith"- accepted view of human nature, yet does not really understand how that can prepare $\mathrm{him} /$ her to guide their moral life in a complex world of inevitable physical, social, cultural change, is left with this "psychic black hole". One of many examples, that could be used today, is the debate on the proposed use of "in vitro fertilization" to conceive human babies. Among the "moral arguments that were used, by those relying on a 'supernatural' source for moral guidance to use or not use this technology, was that these individuals would be 'soul-less' or not really a human being". Medical doctors and scientists, using this technique, could provide the technical knowledge to start the biological processes of conception and development, but by "playing God", they neither had the ability or the moral authority to implant a "soul" into these babies. Today, there are estimated to be over 30,000 such in vitro fertilized human individuals on earth. Are they less "human" than those conceived the "old-fashion" way? Could one really distinguish the naturally-conceived from the artificially-conceived individuals, in any manner possible, via some scientific diagnostic test or patterns of moral behavior, such as "Are these individuals more likely to commit crimes than those conceived the natural manners, or by their acceptance or non-reliance on a supernatural way of knowing?".

Given the unlikelihood of having the vast majority of human beings, who have an entrenched view of one supernatural wellspring for their moral values, it seems the future of integrating scientific facts of human nature into a "bioethical world view" to generate a more humane set of values looks dim. By rejecting a scientific view of their human nature and by not understanding the complex scientific concepts and facts about the origin of the universe, such as: (1) all its physical forces, and the mathematics it would take to give them some foundation for accepting that scientific knowledge; (2) the inter-connectedness of the human being with the physical, chemical, and biological/ecological world; and (3) to understand one of the important concepts to help explain the origin of complex human functions, such as how the conscious mind can emerge from the brain tissue, it is not going to be possible to convince those billions of human beings by education alone. Only when the supernatural icons can be "transformed" to symbolize those views of human nature to be consistent with those of modern sciences, will there be less conflict between these "two cultures" and a chance these "scientifically-transformed supernatural icons" might forge survival values to guide powerful scientific ideas and technologies.

In effect, as with a democracy, which guarantees one's freedom of religion (meaning some faith in a supernatural source of our nature and moral behavior) as a private citizen in our society, so too does it guarantees the freedom from religion, meaning, in the public domain of a pluralistic society/world, no one "supernatural" source of faith can be the sole guide for all. Reason, verifiable scientific facts, ability to make, at least, short-range predictions, based on scientific knowledge and ability for self-correction, should be the primary basis for governing the choices to use or not use new knowledge and technologies. Therefore, if it has to be asked, how could two rational human beings, having the ability to accept the scientific facts, identically, end up with different values. The two cultures gap, of course, could refer to differences in knowing or of accepting scientific facts. Differences 
in accepting scientific facts, can, in principle, be resolved, ultimately. However, the major gap has to be between those who have different values. Therefore, it is important as from whence do these "values" spring? Is there an absolute set of values that can be "taught" or mandated in some fashion to all? The answer seems to be that our individual or collectivized values stem from our unique experiences, which in this author's opinion, help to shape our view of human nature. If that view rejects or denies what all our natural and social sciences tell us about our biological, psychological, social, and cultural attributes, those values will only use science and technology in ways that will ultimately diminish the chances of human survival and higher quality of life. To say this in another way, our unique historic experiences, locked in our primitive brain, trigger unconscious choices, which are then "rationalized" by our modern brain. That "rationalization" can either be shaped by a non-scientific or scientific view of human nature. In other words, do we really have a "free will" or do we have a "self-generated will".

\section{GLOBAL BIOETHICS AS IT RELATES TO “ONE HEALTH, ONE PLANET"}

To bring these rather abstract ideas in focus, let us examine a real human crisis that is in the making. It is a given that all living organisms (microbes, plants, elephants, and human beings) depend on exactly the same fundamental requirements, namely, nutrients, potable water, non-polluted air, limited temperature ranges, low radiation exposure, sufficient calories from food and, in the case of humans, social and cultural environments to maintain dignity and adaptable mental health. The unique range of each of these requirements is different for each species and for the individual within each species. All living organisms need to produce energy from the foods they dependent upon. The foods they depend upon were determined by a long biological evolutionary process to select for genes that allowed for their individual and species survival to reproduce. During the biological evolution of each life form, the foods had to be available within their normal migratory range (fish, birds, tigers, or pre-human primates) or their specific stationary position in a desert, the ocean or jungle (tree, coral reef, and plant) (Milton 2000; Kiple 2000; Teaford and Ungar 2000; Mariani-Costantini 2000; Miller et al. 2000; Paoloni-Giacobino 2003; Calle and Kaaks 2004; Trosko 2007).

For most living organisms, food was obtained during either daylight or nighttime. Food was seasonally obtained. Biological/genetic systems had to adapt to food in a feast/famine fashion. All living organs, prior to human cultural evolution, had to adapt or they perished when the physical environment and food sources changed, which was and is inevitable. Today, with the appearance of human beings and their ability to create cultures, a collision of the slow biological evolution of genes needed for life-sustaining factors to deal with food for energy with the laser-speed cultural evolutionary changes that impact the whole macro-system of food-related elements for survival, we are witnessing the consequences of our biological basis for survival and normal health (Trosko 2007).

With the Diaspora of humans from Africa to Siberia to Australia and to the Americas, we witness the food requirements and biological/cultural adaptations that have occurred, which influenced genetic requirements of Asians, Africans, Caucasians, aboriginals of many continents and islands, etc., as well as their phenotypes, their food acquisition practices, dietary habits, and cuisines. Many of these food-related behaviors were embodied and codified in cultural/religious prescriptions. With the transition from hunter gatherer, the domestication of animals, multiple agricultural practices and increased availability of regular and sufficient calories, human development survived long enough and for sufficient numbers to survive acute diseases (possibly due to 
random genetic factors and to some positive effect of science and medicine, public health policies).

As a result, the median life span, within the last 100 years or so, has reached to almost 85 years in some societies. However, as a consequence of the positive effect of adequate food supply, better sanitation and medical knowledge and public policies, more people are living than are dying. As a result of more people living and living longer in a pluralistic cultural world, each society is impacting the physical and ecosystem environments, which in turn, are affecting the very absolute requirements for life, the global living eco-system [sea life, plant life, microorganisms, including the biologically and culturally adaptation of the gut microbiome (Kau et al. 2011), the fresh water, clean air, earth's temperature patterns, human work systems and dietary patterns, food production, distribution and processing, etc.]. That fundamental and precarious dependence of food for life and good health is being negatively impacted. As a result of the exponential Diaspora of both food and people, as well as other plant and animal species, a real adaptive challenge to the health of the total life ecosystem is evident.

Prior to, and even thousands of years after, the emergence of human culture, unique patters of both acute and some chronic diseases were associated with different cultures. As a result of these recent global changes, we are witnessing major changes in both acute infectious diseases [i.e., HIV (human immunodeficiency virus)/AIDS (acquired immune deficiency syndrome)] and more importantly, chronic diseases in humans ("metabolic diseases"-diabetes, cancer, cardiovascular, etc.), as we, biologically, were never designed to live as long as we now are living. Much of this food-related effects on human health, both positive and negative, has to be attributed to "epigenetic", not "mutagenic" mechanisms (Trosko 2006; Trosko, Chang, and Upham 2002; Trosko et al. 1998).

The old view of one of the human health tragedies was of caloric and nutritional deficiencies to the majority of the world. Today, while that still remains a global problem, global excess of caloric abundance, associated with nutrient-deficient diets, as well as poverty, the global Diaspora of people away from their genetically-adaptive original physical and cultural environments for a growing proportion of the world's population (diabetes in India; different cancer patterns of Japanese in Japan versus those in Seattle; obesity in China; cardiovascular problems in Sicily, etc.) is generating new health problems. In turn, based on a number of political and social factors, food security is becoming a major issue for social unrest when food is not available for the masses (The North Korean's chubby dictator versus the stunted North Korea population).

Currently, there are over seven billion people on Earth. In less than a century, there will be 10 billion persons. That means three billion children will be born during this time. With the known influence that nutrition and diet makes on the health of children, especially during in utero development and neonatal exposures, medical education and global health practices could make a major preventive health care dent in lowering the risks to all kinds of diseases. The current tragedy of seeing increases in childhood chronic diseases, i.e., autism, suggest what David Barker observed decades ago (Barker 2004) that individuals who were at greatest risk to serious chronic diseases had mothers who, for whatever reasons, where exposed to bad nutrition or physical/social environments. This could be one focus for global intervention, i.e., to provide adequate nutritional diets for pregnant women of the world, to lower the risk to preventable chronic diseases in these children. This dynamic and extremely complex interaction of human cultural activities on the genes (mutations) and their expression ("epigenetics") is the basis of the "collision" of our slow biological evolution and our rapid and quixotic cultural evolution that is affecting the human disease patterns we are 
witnessing today, as well as the overall eco-system alteration. Emerging out of this awareness is the new paradigm of "Evolutionary Molecular Medicine" (Nesse et al. 2012).

Finally, what must be done to prevent more needless suffering, due to physical and mental diseases, as well to treat those already afflicted by these diseases when, currently, there is limited resources and, in the future, there will probably be less? Already the injustice done to most on our one planet has not been resolved by the "Mother Theresa" approach of "compassionate" intervention by a few, whose "curiosity" has been limited. On the other hand, those with the richness of knowledge, generated by their "curiosity", also, have failed to use that curiosity-enriched knowledge with wisdon-generated compassion. The "one health-one planet" concept is based on our scientific knowledge. All life is based on the genetic "blueprint", forged in our nucleic acids [DNA/RNA (ribonucleic acid)] by trial and error in a changing earth. A bacterium, a bird, fish, monkey, a rock star, a famous poet, a religious leader, witch doctor, farmer, mother, Nobel prize scientist, and an ordinary folk have unique genetic information, on which their unique, historic environmental factors have interacted. Not one of these unique, individual life forms can escape changes in their genetic information of their reproductive means to their species or to their own individual ability to maintain health. In other words, all life forms cannot resist inevitable changes in our physical, chemical, social, and cultural environments that could either alter our genes or their expression. Change is inevitable in both our genes and our environments. While anaerobic bacteria, by the change caused by the emergence of phytoplankton that changed over eons of the oxygenation of the planet, we humans, created culture, that now is changing the earth's ecosystem in a short while, which is now challenging the survival of most life. It is interesting to note that early aerobic bacteria, found in the deepest sediment in the oceans, have survived the bulk of evolutionary changes that created human culture that is changing the global ecosystem and might even survive any global catastrophy that might eliminate the post-bacterial transition to human culture (Ray et al. 2012).

Therefore, the global task must be to head off the inevitable "train wreck" before us, where, with current scientific knowledge of: (1) our dependency of a sustained ecology to provide adequate calories and nutrients for all to prevent many diseases, is not being implemented; (2) of the consequences of uncontrolled population growth; (3) of the continued lack of educational opportunities for the masses of human beings; and (4) of the persistent lack of justice and humane dignity for too many of the world's population. To rely on "faith", prayer, intuition, and other non-rational or non-scientific means of reasoning to deal with the current and obvious state of global crises is a recipe for disaster. While, scientific reasoning is not foolproof in predicting future events, its predictions can either be tested or self-corrected.

\section{CONCLUSIONS}

Based on the assumption that human actions, shaped by our values, are the direct (conscious or unconscious) consequence of our views of human nature, it seems obvious that most, if not all, of these current theological and political views of human nature have not incorporated scientific knowledge of human biology and evolution of the human cultural animal. These non-scientific views of human nature, in the multiple global religious and political systems, have guided the use/misuse of powerful technologies. As a result, in large part, these unscientific views of human nature are responsible for the deterioration of the global ecosystem on which all life depends and for the global metabolic diseases in human health. In a pluralistic cultural world, with no unified moral philosophy to guide the explosion of new powerful globally-affecting knowledge and technologies, the 
chances to prevent predicted massive human tragedies are slim unless a new view of human nature is universally shared in these different cultural theological/political systems. From a "One Health" perspective, in which the global ecology, animal and human health are inexorably linked, the fundamental concept of how biological and cultural evolution must be incorporated in all of these very different parochial moral views that shape political and economic policies. This analysis provided a number of views of human nature, consistent with current scientific evidence from many scientific disciplines, which now has to be integrated into all cultural institutions, in order that a systems and integrated use of new powerful technologies be examined before their unwise use.

\section{References}

Alexander, R. 1971. "The Search for an Evolutionary Philosophy of Man." Proc. Royal Soc. Vict. 84:99-120.

Barker, D. J. 2004. "The Developmental Origins of Adult Disease." J Am Coll Nutr 236:588s-595s.

Bronowski, J. 1965. Science and Human Values. New York: Harper Torchbooks.

Calle, E. E. and R. Kaaks. 2004. "Overweight, Obesity and Cancer: Epidemiological Evidence and Proposed Mechanisms." Nature Reviews Cancer 4:579-591.

Cassirer, E. 1956. An Essay on Man. New York: Doubleday and Co.

Cordain, L., J. B. Miller, S. B. Eaton, N. Mann, S. H. A. Holt, and J. D. Speth. 2000. "Plant-Animal Subsistence Ratios and Micronutrient Energy Estimates in Worldwide Hunter-Gather Diets." Am. J. Clin. Nutr. 71:682-692.

Cousins, L., W. Karp, C. Lacey, and W. E. Lucas. 1980. "Reproductive Outcome of Women Exposed to Diethylstilbestrol in Utero." Obstetrics and Gynecology 56:70-76.

Dobzhansky, T. 1967. The Biology of Ultimate Concern. New York: The New American Library, Inc.

Drane, J. 1972. "A Philosophy of Man and Higher Education." Main Currents in Modern Thought 29:98-103.

Eisenberg, L. 1973. "On the Humanizing of Human Nature." Impact of Science on Society 23:213-223.

Enis, T. 2008. Science and Nonbelief. Amherst, N.Y.: Prometheus Books.

Flusser, V. 1974. "Walls." Main Currents in Modern Thought 30:136-138
Forrester, D. B. 2000. "Welfare and Human Nature: Public Theology in Welfare Policy Debates." Studies in Christian Ethics 13:1-14.

Geertz, C. 1965. "The Impact of the Concept of Culture on the Concept of Man." In New Views of the Nature of Man, edited by J. Platt. Chicago: University of Chicago Press.

Harris, S. 2012. Free Will. New York: Free Press.

Kau, A. L., P. P. Ahern, N. W. Griffin, A. L. Goodman, and J. I. Gordon. 2011. "Human Nutrition, the Gut Microbiome and Immune System." Nature 474:327-331.

Kiple, K. F., ed. 2000. The Cambridge World History of Food. Cambridge, England: Cambridge University Press.

Koestler, A. 1964. The Act of Creation: A Study of the Conscious and Unconscious in Science and Art. New York: Dell Publishing Comp.

Levine, G. and O. Thomas. 1963. The Scientist and the Humanist. New York: W.W. Norton \& Co., Inc.

Mariani-Costantini, A. 2000. "Natural and Cultural Influences on the Evolution of the Human Diet: Background of the Multifactorial Processes that Shaped the Eating Habits of Western Societies." Nutrition 16:483-486.

Milton, K. 2000. "Back to Basics: Why Foods of Wild Primates Have Relevance for Modern Human Health." Nutrition 16:480-483.

Nesse, R. M., D. Ganten, T. R. Gregory, and G. S. Omenn. 2012. "Evolutionary Molecular Medicine." J. Mol. Med. 90(5):509-522.

Northrop, F. S. C. 1959. The Logic of the Sciences and the Humanities. Cleveland: The World Publishing Company.

Nursall, J. R. 1959. "Oxygen as Prerequisite to the Origin of Metazoan." Nature 183:1170-1172.

Ortega y Gassett, J. 1941. History as a System. New York: Norton.

- 1967. The Origin of Philosophy. New York: W.W. Norton \& Com., Inc.

Otto, M. C. 1947. The Human Enterprise. New York: F.S. Crofts \& Co., Inc.

Paoloni-Giacobino, A., R. Grimble, and C. Pichard. 2003. "Genetics and Nutrition." Clinical Nutrition 22:429-435.

Passmore, J. 1970. The Perfectibility of Man. New York: Charles Scribner's Sons.

Pellegrino, E. D. 1963. "Medicine, History and the Idea of Man." The Annals of the American Academy of Political and Social Science 346(1):9-20.

Platt, J. R. 1972. “A Revolutionary Manifesto." Centers Magazine 5:34-52.

Potter, V. P., D. A. Baerreis, R. A. Bryson, J. W. Curvin, G. Johansen, J. McLeod, ... K. R. Symon. 1970. "Purpose and Function of the University." Science 167:1590-1593.

Potter, V. R. 1971. Bioethics: Bridge to the Future. Englewood, N.J.: Prentice-Hall, Inc. 
1988. Global Bioethics: Building on the Leopold Legacy.

E. Lansing, M.I.: Michigan State University Press.

Ray, H., J. Kallmeyer, R. R. Adhikari, R. Pockalny, B. B. Jergensen, and S. D'Hondt. 2012. "Aerobic Microbial Respiration in 86-Million-Year-Old-Deep-Sea Red Clay." Science 336(6083):922-925.

Rhinelander, P. 1974. Is Man Incomprehensible to Man? San Francisco: W.H. Freeman Co.

Sagan, C. 1995. The Demon-Haunted World: Science as a Candle in the Dark. New York: Random House.

Snow, C. P. 1959. The Two Cultures and the Scientific Revolution. New York: Cambridge University Press.

- 1964. The Two Cultures: And a Second Look. London: Cambridge University Press.

Sperry, R. W. 1975. "Left-Brain, Right Brain." Saturday Review, August 9.

Stent, G. 1969. The Coming of the Golden Age: A View of the End of Progress. Garden City, N.Y.: The Natural History Press.

Taverne, D. 2009. "How Science Upholds Civilization, Human Rights and Democracy." Nature 459:774.

Teaford, M. F. and P. S. Ungar. 2000. "Diet and the Evolution of the Earliest Human Ancestors." Proc. Natl. Acad. Sci. USA 97(25):13506-13511.

Tonsor, J. 1974. "Why John Henry Newman Was Wrong: The Connection Between Moral and Intellectual Virtue in Higher Education." Lecture delivered at the symposium on the Role Ethics in American Life, Bellamine College, January 23.

Trosko, J. E. 1975. “On Making Humane Human Beings in a 'Garbage in-Garbage Out' System.” Interdisciplina 1:1-25.

- 1984. "Scientific Views of Human Nature: Implications for the Ethics of Technological Intervention." Pp. 70-97 in The Culture of Biomedicine, edited by D. H. Brock. Newark: University of Delaware Press.

_. 2002. "Scientific Concepts of Human Nature and Their Implications to Bioethics in a Scientific and
Technologically-Altered World." International Society of Bioethics 9:68-83.

- 2006. "Dietary Modulation of Multi-stage, Multi-mechanisms of Human Carcinogenesis: Effects of Initiated Stem Cells and Cell-Cell Communication." Nutrition and Cancer 54(1):102-110.

_. 2007. "Stem Cells and Cell-Cell Communication in the Understanding of the Role of Diet and Nutrition in Human Diseases." J. Food Hygiene \& Safety 22:1-14.

_ 2014. "Global Health Crises Caused by the Collision of Biological and Cultural Evolution: Pre-natal Influences on Acute and Chronic Diseases Later in Life.”Planet@Risk 2:272-280.

Trosko, J. E., C. C. Chang, and B. L. Upham. 2002. "Modulation of Gap Junctional Communication by 'Epigenetic' Toxicants: A Shared Mechanism in Teratogenesis, Carcinogenesis, Atherogenesis, Immunomodulation, Reproductive- and Neuro-Toxicities." Pp. 445-454 in Biomarkers of Environmentally Associated Disease, edited by S. H. Wilson and W. A. Suk. Boca Raton, F.L.: Lewis Publishers.

Trosko, J. E., C. C. Chang, B. L. Upham, and M. R. Wilson. 1998. "Epigenetic Toxicology as Toxicant-Induced Changes in Intracellular Signaling Leading to Altered Gap Junctional Intercellular Communication." Toxicology Letters 102-103:71-78.

\section{Bio}

James E. Trosko, Ph.D., professor emeritus, Center for Integrative Toxicology, Institute of International Health, Department of Pediatrics and Human Development, College of Human Medicine, Michigan State University; research fields: human genetics, radiation biology, chemical carcinogenesis, global bioethics, epigenetic toxicology, human adult stem cell biology, etc. 